\title{
AN INTERNATIONAL JOURNAL
}

\author{
Vol.: 6 Issue: 4 Year: 2018, pp. 878-897
}

\section{STRATEJIKK KAYNAK KULLANIMININ FİRMA PERFORMANSI ÜZERINDEKİ ETKİSINDE TEDARIKK ZINCİRI ÇEVIKLIIĞINIIN ARACI ROLÜ}

Bülent YILDIZ ${ }^{1}$

Ahmet ÇETINDAŞ ${ }^{2}$
Received Date (Başvuru Tarihi): 25/11/2018

Accepted Date (Kabul Tarihi): 11/12/2018

Published Date (Yayın Tarihi): 04/01/2019

\section{$\ddot{O} Z$}

Bu çalışmada stratejik kaynak kullanımının tedarik zinciri çevikliği ve firma performansı üzerindeki etkisi incelenmiştir. Ayrıca araştırma kapsamında tedarik zinciri çevikliğinin firma performansı üzerindeki etkisi analiz edilmiştir. Bu amaçla Türkiye'nin ilk 1000 ihracatçı firması arasından 115 firmadan anket tekniği ile veri toplanmıştır. Araş̧tırmada öncelikle, kullanılan ölçeklerin yap geçerliği ve güvenilirliğini test etmek amactyla keş̧fedici ve doğrulayıcı faktör analizleri ile güvenilirlik analizi yapılmışsır. Araşstırma hipotezlerini test etmek amacıyla 115 firmadan elde edilen veriler yapısal eșitlik modeli ile analiz edilmiștir. Yapılan analizler sonucunda stratejik kaynak kullanımının tedarik zinciri çevikliği ve firma performansını pozitif yönde anlaml olarak etkilediği bulgusuna ulaşılmuştır. Tedarik zinciri çevikliğinin de firma performansı pozitif yönde anlamlı olarak etkilediği tespit edilmişstir. Çalışma kapsamında ayrıca stratejik kaynak kullanımının firma performansı üzerindeki etkisinde tedarik zinciri çevikliğinin aracllık rolü araştırllmıştır. Aracılık testi neticesinde tedarik zinciri çevikliğinin kısmi aracılık rolü olduğu bulgusuna ulaşılmıştır.

Anahtar Kelimeler: Stratejik Kaynak Kullanımı, Tedarik Zinciri Çevikliği, Firma Performansı JEL Kodları: L25, M11, O14

\section{THE MEDIATING ROLE OF SUPPLY CHAIN AGILITY IN THE EFFECT OF STRATEGIC RESOURCE USAGE ON THE COMPANY PERFORMANCE}

\begin{abstract}
In this study, the effects of strategic resource utilization on supply chain agility and firm performance were examined. In addition, the impact of supply chain agility on firm performance was analyzed. For this purpose, the data was collected from 115 companies among Turkey's top 1000 exporters with survey technique. Initially, exploratory and confirmatory factor analysis and reliability analysis were conducted to test the construction validity and reliability of the scales used. To test the research hypotheses, the data obtained from 115 companies were analyzed by the structural equation model. As a result of the analyzes, it was found that the use of strategic resource significantly affected the supply chain agility and firm performance. Supply chain agility was also found to have a significant effect on firm performance. The study also explored the role of supply chain agility as a mediator in the impact of strategic resource utilization on firm performance. As a result of the mediation test, it was found that supply chain agility has a partial mediation role.
\end{abstract}

Keywords: Strategic Resurce Usage, Supply Chain Agility, Firm Performance JEL Kodları: L25, M11, O1

\footnotetext{
${ }^{1}$ Dr. Öğr. Üyesi Kastamonu Üniversitesi dr.yildiz.bulent@gmail.com

${ }^{2}$ Dr. Öğretim Üyesi Hasan Kalyoncu Üniversitesi ahmet.cetindas@hku.edu.tr
}

http://orcid.org/0000-0002-5368-2805 http://orcid.org/0000-0003-2262-4204 


\section{GİRIȘ}

Tedarikçi seçiminde firmanın gereksinimlerine ve uzun vadeli ihtiyaçlarına en uygun olanları etkili bir şekilde ayırt etmek önemlidir. Tedarikçi değerlendirmesi ve seçimi, tedarikçinin seçim kriterlerine göre özelliklerinin değerlendirilmesini ve ürünün gereksinimlerine en uygun tedarikçinin seçilmesini içeren tedarikçinin gerçek seçimiyle ilgilidir. $\mathrm{Bu}$ değerlendirme kriteri çok önemlidir, çünkü herhangi bir tek tedarikçinin performansının tüm boyutlarında mükemmel olması zordur. Tedarikçi izleme, tedarikçi performansını takip eder ve iyileştirme için tedarikçilere geri bildirim sağlar. Sonuçta ise stratejik kaynak performansını iyileştirir (Chan ve Chin, 2007: 1395).

Stratejik kaynak kullanımı, firmaların uzun vadeli hedeflerine ulaşmasına yardımcı olan ve değer katan sistematik ve kapsamlı bir süreçtir (Chan ve Chin, 2007: 1392). Stratejik kaynak kullanımı, firma hedefleri ile uyumlu satın alma ve tedarik metrikleri, paranın nerede harcandığ konusunda kapsamlı bilgi, tedarik zincirinin tam olarak bilinmesi ve anlaşılması, aktif olarak yönetilen tedarik üssü, optimize edilmiş tedarik üssü, bağlantılı talep ve ikmal planlaması, entegre organizasyon yapıları, stratejik odaklı işgücü ve devamlı gelişme konularını içermektedir (Hawkins vd., 2014:224). Stratejik kaynak kullanımı, tedarikçilerin uzun vadeli ortaklıklar için belirlenmesini ve seçilmesini amaçlamakta, tedarikçi performansını ve tedarikçilerin performansını arttırmak için kaynakları etkin bir şekilde tahsis ederek tedarikçilerin erken katılımını ve tedarikçiyi geliştirmeyi hedeflemektedir. Stratejik kaynak kullanımı, firmanın rekabetçi profilini korur ve zinciri oluşturan halkaları geliştirir, birleştirir ve yönetir (Khan vd., 2008: 1509). Stratejik kaynak kullanımında, kaynak yöneticileri, çalışan ilişkilerini geliştirmede ve tedarikçilerle etkin iletişimde çok önemli bir rol oynamaktadır. Bir firmanın önemli bir kaynağı olan stratejik tedarik, firmanın alıcı-tedarikçi işbirliği ile ek kaynaklara erişmesine, edinmesine ve geliştirmesine yol açar ( $\mathrm{Su}, 2013: 26)$. Stratejik kaynak kullanımı, tedarikçinin seçimine stratejik bir yaklaşım getirmeyi de içermekte, firmanın stratejik hedefleriyle daha uyumlu bir yaklaşım benimsemekte ve kaynağın kurumsal stratejiyle bütünleşmesini yansıtmaktadır (Landale vd., 2018:3). Başarılı firmalar, sadece şirket içi ArGe'de değil, tedarikçiler, taşeronlar ve hizmet firmaları ile etkin ilişkilerde "stratejik kaynaklara" yatırım yapanlardır (Belussi vd., 2010: 712).

Geçmişte yapılan araştırmalar, stratejik kaynakların bazı unsurlarının çeviklikle pozitif ilişkili olduğunu ileri sürmüştür (Nayyar ve Bantel, 1994; Goldman vd. 1994; Teece vd. 1997). $\mathrm{Bu}$ ilişki, artan alıcı-tedarikçi ilişkilerine bağlanmış, talep ve arz bilgilerinin değişimini kolaylaştırarak, kurumlar arası güvenin gelişmesine yardımcı olmuştur (Chiang vd., 2012:56). 
Çeviklik kavramı, yönetsel uygulamadaki önemi nedeniyle üretim ve tedarik zinciri yönetimi araştırmalarında giderek artan bir ilgi yaşamıştır. Tedarik zinciri çevikliği, firmaların değişikliklere uyum sağlamasına ve tüm tedarik zinciri boyunca hızlı yanıt vermesine olanak veren dinamik bir yetenek olarak düşünülebilir. Böylece tedarik zinciri çevikliği, tek bir firmanın ötesine uzanır ve büyük müşteriler ve tedarikçiler ile uyumlaştırmayı içerir (Sanchez ve Leo, 2018: 266).

Günümüzün dünyasında, tedarik zincirleri değişen ürünlere, düşük maliyetlere, kısa yaşam döngüsüne ve daha iyi kaliteye sahip ürünler sunma gibi rekabet gücü ile değişen pazarlardaki ustalığa odaklanmaktadır (Bidhandi ve Valmohammadi, 2017: 1066). Tedarik zinciri çevikliği iş seviyesinde hız ile ilgili olarak dışarıdan odaklanmış bir yetkinliği temsil ederken, hızlı pazar duyarlılığı, teslim süresini azaltma, teslimat güvenilirliği ve ürün tanıtımı sıklığı gibi faaliyetlerle ilgilidir (Um, 2017:467). Tedarik zinciri çevikliği, değişen pazar ortamına hızlı bir şekilde cevap vermek için tedarik zinciri yeteneğini ele almaktadır. Bir sonucu veya dışsal odaklı bir kavramı temsil eder ve bu nedenle bir yetkinlikten ziyade bir yetenek olarak kabul edilir (Swafford vd., 2006:176).

Tedarik zinciri çevikliği, bir firmanın iç tedarik zinciri işlevlerinin pazardaki belirsizliğe cevap vererek stratejik bir avantaj sağlama yeteneğini temsil eder ve bir firmanın rekabet stratejisinin anahtar unsuru olarak kabul edilir. Tedarik zincirini hızlı ve çeşitli çevresel ve rekabetçi değişikliklere karşı harekete geçirebilecek yetenekler edinerek sistematik olarak geliştirilir (Khan vd., 2008: 1511-1512). Tedarik zinciri çevikliği kavramı, kolayca uygulanabilecek veya taklit edilebilecek kurallar ve prosedürler değil, tedarik zinciri boyunca farklı kanal üyeleri arasındaki koordinasyon ve entegrasyon hakkında karmaşık bir felsefeyi yansitmaktadır (Liu vd., 2013:1453).

Tedarik zinciri çevikliği, firma performansını iyileştirmek için kritik olan, nadir, değerli ve kusurlu olmayan bir operasyonel yetenek olarak hareket edebilir. Özellikle tedarik zinciri çevikliği, bir firmanın bilgi entegrasyonu yoluyla yüksek müşteri duyarlılığı ve ana pazar değişikliklerine ulaşmasına yardımcı olabilir. Bu entegrasyon, tedarik zincirinin görünürlüğünü arttırır ve firmanın pazar yeri değişikliklerini gerçek zamanlı olarak algılamasını sağlar ve böylece talep belirsizliğinin maliyetini düşürür. Tedarik zinciri çevikliğii, firmanın sadece günlük operasyonlarını iyileştirmesini sağlamaz, aynı zamanda maliyetleri düşürmesine ve karlılı̆̆ artırmasına da yardımcı olur (Liu vd., 2013:1453). 


\section{LITERATÜR TARAMASI VE ARAŞTIRMA HIPOTEZLERININ} KURULMASI

\subsection{Stratejik Kaynak Kullanımı İle Firma Performansı İlişkisi}

İşletmeler satın almayı stratejik planlarına dahil ederek elde edecekleri faydaları ve rekabet avantajlarını fark ettiğinden dolayı bu konu bir çok bilimsel çalışmaya konu olmuştur (Sinha vd. 2011; Kang vd. 2009; Paulraj ve Chen, 2007a; Tan vd. 2002).

Stratejik kaynak kullanımı, işletmelerin etkin maliyet yönetimine değer katarak, tedarik eğilimleri hakkında değerli bilgiler sunarak ve önemli tedarikçilerle yakın ilişkiler kurmasını sağlayarak rekabet avantajları elde etmelerine yardımcı olur. Böylelikle, firmalar daha iyi kararlar almak ve firmanın kar marjlarını artırmak için stratejik kaynak kullanımını tercih ederler (Sinha vd. 2011).

Stratejik kaynak kullanımı ve firma performansı arasındaki ilişki başta üretim işletmeleri olmak üzere birçok çalışmada incelenmiştir (Carr ve Pearson, 1999; 2002; Carr ve Smeltzer, 1999; Chen vd. 2004; Jin ve Farr, 2010; Narasimhan ve Das, 1999a). Su ve Garheya (2012) ABD’li 152 tekstil firması üzerinde yaptığı çalışmada stratejik kaynak kullanımının aktif karlılık, kar marjı ve pazar payı olarak ele aldığı firma performansına pozitif yönde anlamlı etki ettiğini tespit etmiştir. Benzer şekilde Kim, Suresh ve Kocabasoglu-Hillmer (2015)'de stratejik kaynak kullanımının finansal, operasyonel ve tedarik zinciri performanslarına pozitif yönde anlamlı etki ettiğini ıspatlamıştır.

Satın alma sürecinin stratejik planlar ve faaliyetler içerisinde bulunması gerektiği ve bu şekilde işletme performansını arttıracağı iddiasıyla çalışmanın ilk hipotezi şu şekilde kurulmuştur:

H1: Stratejik kaynak kullanımı firma performansını pozitif yönde anlamlı olarak etkiler.

\subsection{Stratejik Kaynak Kullanımı İleTedarik Zinciri Çevikliği İlişkisi}

Tedarik zinciri çevikliği, işletmelerin rekabet stratejilerinin anahtar unsuru olarak kabul edilir (Nayyar ve Bantel, 1994; Goldman vd. 1994; Teece vd. 1997) ve bir organizasyonun iç tedarik zinciri işlevlerinin, pazardaki belirsizliğe cevap vererek stratejik bir avantaj sağlama yeteneğini temsil eder. Firmalar farklı stratejiler kullanarak rekabet avantajı elde ettikleri gibi, tedarik zinciri çevikliği de farklı yollarla sağlanabilir.

Çeviklik kavramsal olarak esneklikle karıştırılabilir olsa da temelde çok farklıdır. Çeviklik, çabukluk ve beceri ile ilgilidir; esneklik ise uyarlana bilirlik ve çok yönlülük ile 
ilgilidir. Yani çeviklik, değişime karşılık verilen reaksiyon süresini, esneklik ise değişime karşı1ık verilen reaksiyon kabiliyetini ifade eder.

Stratejik kaynak kullanımını farklı alt boyutlarda inceleyen çalışmalar olsa da, bu çalışmada stratejik satın alma üzerinde durulmuştur. Stratejik satın alma, satın alma işlevinin stratejik ve proaktif tarafını yansıtarak, işletmelerin çeşitli planlama süreçlerinde, seçilmiş tedarikçilerle yakın ve birlikte çalışılmasını mümkün kılar. Benzer şekilde, satın alma işlevini stratejik olarak yapan firmalar, pazar talep değişiklikleri hakkında tedarikçileriyle hızlı bir şekilde iletişim kurar, tedarikçilerin değişen tedarik ihtiyaçlarını karşılayabilmesini ve planlamanın müşterinin ihtiyaçlarına ve beklentilerine yanıt vermesine yardımcı olmasını sağlar. Bunu dikkate alan araştırmalar, stratejik kaynak kullanımının bazı unsurlarının çeviklikle pozitif yönde ilişkili olduğunu ileri sürmüştür (Khan ve Pillania, 2008; Mason vd. 2002; Narasimhan ve Das, 1999a; Paulraj ve Chen, 2007b).

Narasimhan ve Das (1999a) stratejik kaynak kullanımının, çeviklikle alakalı olan, değişim esnekliği olarak adlandırdığı, üretim sürecinin daha küçük tasarım değişiklikleri ile ürünleri özelleştirebilme yeteneğini pozitif yönde etkilediğini ispatlamıştır. Ayrıca değişim esnekliğinin, bir performans kriteri olarak kabul edilen üretim maliyetini düşürdüğü bulgusuna ulaşmıştır. Stratejik kaynak kullanımını stratejik tedarikçi ortaklığı, tedarik esnekliği, tedarikçinin değerlendirilmesi ve tedarik zinciri üyelerine olan güven boyutlarıyla inceleyen Khan ve Pillania (2008), tüm bu boyutların tedarik zinciri çevikliğini ve firma performansını pozitif yönde anlamlı olarak etki ettiğini bulmuştur. Chiang, Kocabasoglu-Hillmer ve Suresh (2012) stratejik kaynak kullanımı ve stratejik esnekliğin tedark zinciri çevikliği üzerinde pozitif etkisi olduğunu tespit etmiştir.

Stratejik kaynak kullanımında, satın alma işlevinin stratejik olarak planlanması ve yürütülmesi sebebiyle işletmelere çeviklik kazandıracağından ve önceki çalışmalarda 1spatlanan ilişkiler göz önünde bulundurulduğunda stratejik kaynak kullanımının tedarik zinciri çevikliğine etki etmesi beklenmekte olup çalışmanın ikinci hipotezi şu şekilde kurulmuştur:

H2: Stratejik kaynak kullanımı tedarik zinciri çevikliğini pozitif yönde anlamlı olarak etkiler.

\subsection{Tedarik Zinciri Çevikliği İle Firma Performansı İlişkisi}

Rekabet eden firmalar için söylenen "büyük olan küçüğü yer" söylemi, işletme çevrelerinin sürekli değişmesi ve rekabetin artarak daha dinamik bir hal almasıyla birlikte yerini “hızlı olan yavaşı yer” söylemine bırakmıştır (Jennings ve Haughton, 2002). 
Daha önceki araştırmalarda tedarik zinciri çevikliği ve firma performansı arasında doğrudan bir ilişki olduğunu kanıtlamıştır (Tallon ve Pinsonneault, 2011; Swafford vd. 2008; Yusuf ve Adeleye, 2002).

Yusuf ve Adeleye (2002) firmaları çevik ve yalın olarak sınıflandırmış ve çevik olan firmaların daha yüksek performans gösterdiğini tespit etmiştir. DeGroote ve Marx (2013) ise tedarik zinciri çevikliğini değişimi algılama ve değişime cevap verme şeklinde boyutlandırmış ve her iki boyutun firma performansını geliştirdiğini tespit etmiştir.

Çalışkan, Karacasulu ve Öztürkoğlu (2016), hızlı moda markalarında 3 boyutlu olarak incelediği tedarik zinciri çevikliğinin (değişikliklere cevap verebilme hızı, müşteri hizmet hızı ve piyasaya yeni ürün sürme hızı) 4 boyutlu firma performansına (satış performansı, müşteri memnuniyeti, ürün ve servis kalitesi ve karlılık performansı) etkisini incelemiş ve tedarik zinciri çevikliğinin tüm performans boyutlarını etkilediğini bulmuştur. Ayrıca tedarik zinciri çevikliği boyutlarından müşteri hizmet hızının satış performansına, müşteri memnuniyeti performansına, ürün ve servis kalitesi performansına pozitif etki ettiğini, yeni ürün sürme hızının ise müşteri memnuniyeti performansına, ürün ve servis kalitesi performansına ve karlılık performansına pozitif etki etiğini bulmuştur.

Üretim yönetimi ve tedarik zinciri yönetimi literatürü de çeviklik ve finansal performans arasında pozitif bir ilişki olduğunu göstermektedir. Finansal performans, aktif karlılığı, satış getirileri ve yatırımın geri dönüşü gibi birkaç boyutta değerlendirilebilir. Kısacası çevik üretimin de finansal performans üzerinde doğrudan olumlu bir etkisi olduğu birçok çalışmada tespit edilmiştir (Vazquez-Bustelo vd. 2007; Inman vd. 2011).

Gligor ve Holcomb (2012) tedarik zinciri çevikliğinin ilişkisel performans ve operasyonel performans üzerindeki etkisini incelemiş ve tedarik zinciri çevikliğinin her ikisini de pozitif yönde anlamlı olarak etkilediğini bulmuştur. Blome, Schoenherr ve Rexhausen (2013) tedarik zinciri çevikliğinin operasyonel performans üzerinde pozitif yönde etkisi olduğunu ispatlamıştır. Ancak Gligor, Esmark ve Holcomb (2015) tedarik zinciri çevikliğinin finansal performansı etkilemediğini, yine de müşteri ve maliyet etkinliği ile pozitif ilişkisi olduğunu ispatlamıştır. Yang (2014) ise tedarik zinciri çevikliğinin maliyet etkinliğini pozitif yönde anlamlı olarak etkilediğini ancak firma performansı üzerinde bir etkisinin olmadığını raporlamıştır.

Tüm bu çalışmalar dikkate alındığında tedarik zinciri çevikliğinin firma performansına etki edeceği düşünüldüğünden bir sonraki hipotez şu şekilde belirlenmiştir: 
H3: Tedarik zinciri çevikliği firma performansını pozitif yönde anlamlı olarak etkiler.

\subsection{Tedarik Zinciri Çevikliğinin Aracı Rolü}

Stratejik kaynak kullanımının performansı doğrudan etkileyeceği düşüncesinin yanı sıra, tedarik zinciri çevikliğinin bu ilişkide aracılık rolü olduğu ve etkiyi arttıracağı düşünüldüğünden tedarik zinciri çevikliğinin aracılığının incelenmesi gerektiğgi düşünülmüştür. Literatürde bu düşünceyi destekleyen, tedarik zinciri çevikliğinin aracılık rolünü inceleyen bazı çalışmalar mevcuttur. Örneğin Vickery vd. (2010) tedarik zinciri bilgi teknolojisi ve tedarik zinciri örgütsel girişimleri ile firma performansı arasında, çevikliğin aracılık rolünü test etmiştir. Bağımsız değişkeni ayrı ayrı ve birlikte ele aldığı iki model kurmuş ve her ikisinde de çevikliğin aracılık rolünü ispatlamıştır. Benzer şekilde Swafford vd. (2008) de bilgi teknolojileri ve rekabetçi işletme performansına entegrasyon değişkenleri arasında tedarik zinciri çevikliğinin aracılık rolüne bakmış ve tedarik zinciri esnekliği ile rekabetçi işletme performansı arasındaki ilişkide, tedarik zinciri çevikliğinin aracılık rolünü tespit etmiştir. Blome, Schoenherr ve Rexhausen (2013) arz yönlü yetkinliğin operasyonel performans üzerindeki etkisinde tedarik zinciri çevikliğinin aracılık rolünü bulgulamıştır.

Chan, Ngai ve Moon (2017) çalışmasında kaynak esnekliği ve koordinasyon esnekliğinin tedarik zinciri çevikliğine ve firma performansına etkisini ve tedarik zinciri çevikliğinin firma performansına etkisini tespit etmiş, ayrıca tedarik zinciri çevikliğinin stratejik esneklik ve üretim esnekliği ile firma performansı arasında ki ilişkiye aracılık ettiğini ispatlamıştır. Bunun dişında, Chiang, Kocabasoglu-Hillmer ve Suresh (2012) stratejik kaynak kullanımının tedarik zinciri çevikliği üzerindeki etkisinde stratejik esnekliğin aracı etkisini araştırdığında sadece kısmi aracılık bulmuştur.

Tedarik zinciri çevikliğinin değişimlere hızlı tepki veren doğası, işletmeleri hedeflerine ulaştırmak için stratejik kaynak kullanımı kabiliyetlerini genişleterek stratejik ve operasyonel eylemlerini daha çevik yürütmelerini ve sonuç olarak daha yüksek performans sergilemelerini sağlar. Bu yüzden, stratejik kaynak kullanımının firma performansı üzerindeki etkisinde tedarik zinciri çevikliğin aracılığının bu etkiyi daha iyi açıklayacağına olan inancımız sebebiyle bir sonraki hipotez şu şekilde kurulmuştur:

H4: Stratejik kaynak kullanımının firma performansı üzerindeki etkisinde tedarik zinciri çevikliğinin aracılık rolü bulunmaktadır. 


\section{ARASTTIRMANIN YÖNTEMI}

\subsection{Araștırmanın Modeli}

Araştırmanın modeli Şekil 1'de verilmiştir.

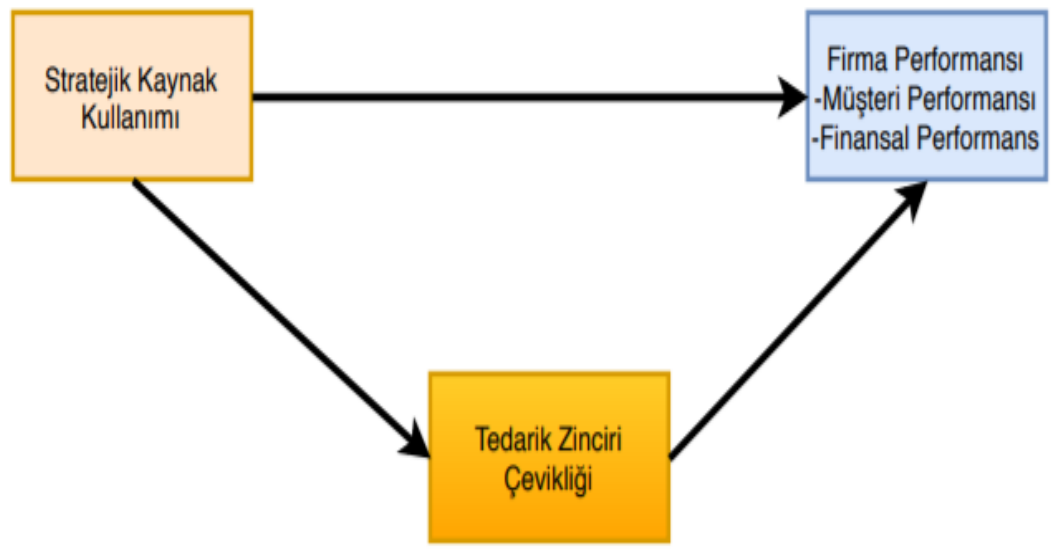

Şekil 1: Araştırmanın Modeli

\subsection{Araştırmanın Ölçekleri}

Stratejik kaynak kullanımı ve tedarik zinciri çevikliği ölçekleri Kim ve Chai (2017) çalışmasından alınmıştır. Müşteri performansı soruları Hwang vd. (2015), Kafetzopoulos vd. (2013), Kafetzopoulos vd. (2015) ve De Guimarães vd. (2016) çalışmalarından faydalanılarak hazırlanmıştır.

\subsection{Araştırmanın Evren ve Örneklemi}

Araştırmanın evreninin Türkiye'nin ilk 1000 ihracatçı firması oluşturmaktadır. Araştırmanın örneklemini ise bu firmalar arasından veri elde edilebilen 115 ihracatçı firma oluşturmaktadır. Araştırma verileri surveey.com internet sitesi üzerinden oluşturulan anket formunun online olarak firmalara mail ile gönderilmesi sonucu geri dönüş yapan 115 firmadan elde edilen verilerden meydana gelmektedir. Veriler Nisan 2018- Temmuz 2018 arasında toplanmıştır.

\section{4. Ölçeklerin Yapı Geçerliği ve Güvenilirliği}

Ölçeklerin yapı geçerliği ve güvenilirliğini test etmek amacıyla öncelikle keşfedici faktör analizi (KFA) ve doğrulayıcı faktör analizleri (DFA) yapılmış ardından da güvenilirlik analizi yapılmıştır.

Keşfedici faktör analizi sonucu elde edilen faktör yükleri Tablo 1'de verilmiştir. 
Tablo 1: Ölçek Maddelerinin Faktör Yükleri

\begin{tabular}{|c|c|}
\hline Stratejik Kaynak Kullanımı Maddeler & Faktör Yükleri \\
\hline SKK1: Satın alma, firmanın stratejik planlama sürecine dahildir. & .728 \\
\hline SKK2: Satın alma birimi, firmanın stratejik hedefleri hakkında iyi bilgi sahibidir. & .831 \\
\hline SKK3: Satın alma performansı, firmanın başarısına katkıları açısından ölçülür. & .828 \\
\hline $\begin{array}{l}\text { SKK4: Satın alma uzmanlarının gelişimi, rekabetçi stratejinin unsurlarına } \\
\text { odaklanır. }\end{array}$ & .871 \\
\hline $\begin{array}{l}\text { SKK5: Satın alma departmanı, satın alma işlevinde bütünleyici bir rol } \\
\text { oynamaktadır. }\end{array}$ & .644 \\
\hline Tedarik Zinciri Çevikliği Maddeler & Faktör Yükleri \\
\hline $\begin{array}{l}\text { TZÇ3: Tedarikçilerle müşterek planlama; satın alma, üretim ve lojistik } \\
\text { konularında önemlidir. }\end{array}$ & .755 \\
\hline $\begin{array}{l}\text { TZÇ4: Tedarikçiler, lojistik hizmet sağlayıcıları ve tedarik zincirindeki } \\
\text { müşterilerle bilgi entegrasyonu önemlidir. }\end{array}$ & .645 \\
\hline TZÇ5: Müşteri hizmet seviyemizi geliştirmek yüksek önceliklidir. & .827 \\
\hline TZÇ6: Teslimat güvenilirliğini geliştirmek yüksek bir önceliktir. & .761 \\
\hline $\begin{array}{l}\text { TZÇ7: Değişen pazar ihtiyaçlarına cevap vermenin arttırılması yüksek bir } \\
\text { önceliktir. }\end{array}$ & .764 \\
\hline \multicolumn{2}{|l|}{ Firma Performansı } \\
\hline Müşteri Performansı & Faktör Yükleri \\
\hline MP1: Firmamızın son üç yılına göre müşteri memnuniyeti artmıştır. & .791 \\
\hline MP2: Son üç y1la göre müşteri şikayetlerine cevap verme süresi azalmıştır. & .615 \\
\hline MP3: Son üç y1la göre müşterilerin firmaya bağlılı̆̆ & .842 \\
\hline MP4: Son üç yıla göre müşterilerin markalarımıza karşı sadakati artmıştır. & .829 \\
\hline $\begin{array}{l}\text { MP5: Son üç yıla göre müşterilerimiz gözünde ürünlerimizin güvenilirliği } \\
\text { artmıştır. }\end{array}$ & .742 \\
\hline Finansal Performans & Faktör Yükleri \\
\hline FP1: Firmamızın son üç yılına göre karlılığımız artmıştır. & .849 \\
\hline FP2: Son üç yıla göre satışlarımız yükselmiştir. & .889 \\
\hline FP3: Son üç yıla göre pazar payımız artmıştır. & .885 \\
\hline FP4: Son üç yıla göre yatırımlarımızın getirisi artmıştı & .888 \\
\hline
\end{tabular}

KFA sonucu stratejik kaynak kullanımı ile tedarik zinciri çevikliği ölçeklerinin tek boyutlu, firma performansı ölçeğinin ise iki boyutlu yapıya sahip olduğu görülmüştür. Stratejik kaynak kullanımı ölçeği faktör yükleri 0,644 ile 0,871 arasında elde edilmiştir. Tedarik zinciri çevikliği ölçeğinin TZÇ1: Tedarik zincirimiz, talepteki değişimlere, aşırı satışlar veya kayıp satışlar olmadan cevap verebilir, TZÇ2: Tedarik zincirimiz piyasa talebini tahmin edebilmekte ve reel piyasa talebine cevap verebilmektedir ve TZÇ8: Envanter ve talep seviyeleri tedarik zinciri boyunca görünür durumdadır maddeleri faktör yükleri düşük çıktığı için analizden çıkarılmıştır. Ölçeğin faktör yükleri 0,645 ile 0,827 arasında elde edilmiştir. Firma performansı ölçeği faktör yükleri müşteri performansı boyutu için 0,615 ile 0,842 arasında ve finansal performans boyutu için ise 0,849 ile 0,889 arasında elde edilmiştir. Stratejik kaynak kullanımı ölçeği KMO testi neticesinde örneklem yeterlilik değerinin 0,829 olduğu ve örneklem büyüklüğünün faktör analizi için yeterli olduğu bulgusu elde edilmiştir. Ayrıca, Bartlett küresellik testinin anlamlı olmas1 $[\chi 2(10)=229.072, \rho<0.01]$ maddeler arasındaki korelasyon ilişkilerinin faktör analizi için uygun olduğunu göstermektedir. Tedarik zinciri çevikliği ölçeği KMO testi neticesinde örneklem yeterlilik değerinin 0,777 olduğu ve örneklem büyüklügünün 
faktör analizi için yeterli olduğu bulgusu elde edilmiştir. Ayrıca, Bartlett küresellik testinin anlamlı olması $[\chi 2(10)=182.108, \rho<0.01]$ maddeler arasındaki korelasyon ilişkilerinin faktör analizi için uygun olduğunu göstermektedir. Firma performansı ölçeği için KMO testi neticesinde örneklem yeterlilik değerinin 0,760 olduğu ve örneklem büyüklüğünün faktör analizi için yeterli olduğu bulgusu elde edilmiştir. Ayrıca, Bartlett küresellik testinin anlamlı olması $[\chi 2(36)=604.843, \rho<0.01]$ maddeler arasındaki korelasyon ilişkilerinin faktör analizi için uygun olduğunu göstermektedir.

KFA sonrası DFA yapılmıştır. DFA sonucu elde edilen uyum iyiliği değerleri Tablo 2'de sunulmuştur.

Tablo 2: DFA Uyum İyiliği Değerleri

\begin{tabular}{|l|l|l|l|l|l|l|l|}
\hline Değişken & $\mathbf{X}^{\mathbf{2}}$ & df & CMIN/df & GFI & CFI & TLI & RMSEA \\
\hline Stratejik Kaynak Kullanımı & 7.928 & 5 & 1.586 & 0.972 & 0.987 & 0.974 & 0.072 \\
\hline Tedarik Zinciri Çevikliği & 3.671 & 4 & 0.918 & 0.988 & 1.000 & 1.000 & 0.000 \\
\hline Firma Performansı & 33.893 & 21 & 1.614 & 0.941 & 0.978 & 0.963 & 0.073 \\
\hline
\end{tabular}

DFA sonucu ölçeklerin uyum iyiliği değerlerini sağladığı ve iyi uyum gösterdiği görülmektedir.

KFA ve DFA sonrasında ölçekler için güvenilirlik analizi yapılmış ve analiz sonuçları Tablo 3'de verilmiştir.

Tablo 3: Güvenilirlik Analizi

\begin{tabular}{|c|c|c|}
\hline Değişken & Cronbach Alpha Katsayısı & Madde Sayısı \\
\hline Stratejik Kaynak Kullanımı & 0,842 & 5 \\
\hline Tedarik Zinciri Çevikliği & 0,806 & 5 \\
\hline Firma Performansı & 0,842 & 5 \\
\hline Müşteri Performansı & 0,820 & 4 \\
\hline Finansal Performans & 0,911 & 9 \\
\hline
\end{tabular}

Güvenilirlik analizi sonucu ölçeklerin yüksek güvenilirliğe sahip olduğu bulgusuna ulaşılmıştır.

\subsection{Araştırmanın Bulguları}

$\mathrm{Bu}$ kısımda öncelikle araştırmaya katılan firmalara ait bazı demografik bulgular aktarılmıştır. Ardından korelasyon analizine ilişkin bulgular verilmiş ve son olarak da araştırma hipotezlerini test etmek amacı ile yapılan yapısal eşitlik modeli analizi sonuçlarına değinilmiştir.

Firmaların faaliyet alanlarına ilişkin bulgular Tablo 4'de verilmiştir. 
Tablo 4: Firmaların Faaliyet Alanı

\begin{tabular}{|c|c|c|c|}
\hline FAALIYET ALANI & Frekans & Yüzde & Kümülatif Yüzde \\
\hline Gida & 28 & 24.3 & 24.3 \\
\hline Tekstil & 16 & 13.9 & 38.3 \\
\hline Plastik/Kimya & 14 & 12.2 & 50.4 \\
\hline Makine & 9 & 7.8 & 58.3 \\
\hline İnşaat & 10 & 8.7 & 67.0 \\
\hline Elektronik & 4 & 3.5 & 70.4 \\
\hline Diğer & 34 & 29.6 & 100.0 \\
\hline Toplam & 115 & 100.0 & \\
\hline
\end{tabular}

Firmaların 28'i gıda, 16'sı tekstil, 14'ü plastik/kimya, 10'u inşaat, 9'u makine, 4'ü elektronik sektöründe faaliyet göstermekte olup 34 firma bu sektörler dişında faaliyette bulunmaktadır.

Anketi cevaplandıran firma çalışanlarının çalıştıkları pozisyona ilişkin bulgular Tablo 5'de verilmiştir.

Tablo 5: Çalışılan Pozisyona İlişkin Bulgular

\begin{tabular}{|c|c|c|c|}
\hline POZISYON & Frekans & Yüzde & Kümülatif Yüzde \\
\hline Pazarlama Müdürü & 20 & 17.4 & 17.4 \\
\hline Üretim Müdürü & 12 & 10.4 & 27.8 \\
\hline Ar-Ge Müdürü & 27 & 23.5 & 51.3 \\
\hline Satın alma Müdürü & 12 & 10.4 & 61.7 \\
\hline Kalite Müdürü & 6 & 5.2 & 67.0 \\
\hline Firma Sahibi / Ortağ1 & 2 & 1.7 & 68.7 \\
\hline Diğer & 36 & 31.3 & 100.0 \\
\hline Toplam & 115 & 100.0 & \\
\hline
\end{tabular}

Anketi cevaplandıran firma çalışanlarının 27'si Ar-Ge Müdürü, 20'si Pazarlama Müdürü, 12'si Üretim Müdürü, 12'si Satın alma Müdürü, 6's1 Kalite Müdürü, 2'si Firma Sahibi /Ortağı olarak görev yapmakta olup 36'sı bu pozisyonlar dışındaki görevlerde çalışmaktadır.

Firma çalışanlarının firmadaki çalışma sürelerine ilişkin bulgular Tablo 6'da verilmiştir.

Tablo 6: Çalışma Süresine İlişkin Bulgular

\begin{tabular}{|c|c|c|c|}
\hline ÇALIŞMA SÜRESİ & Frekans & Yüzde & Kümülatif Yüzde \\
\hline $0-5$ yıl & 36 & 31.3 & 31.3 \\
\hline 6-15 y1l & 64 & 55.7 & 87.0 \\
\hline 16 y1l üzeri & 15 & 13.0 & 100.0 \\
\hline Toplam & 115 & 100.0 & \\
\hline \multicolumn{3}{|r}{} \\
\hline
\end{tabular}


Firma çalışanlarının 64'ü 6-15 yı1, 36'sı 0-5 yıl arası ve 15'i ise 16 yıl ve üzeri firmada görev yapmaktadır.

Firma çalışanlarının öğrenim durumuna ilişkin bulgular Tablo 7'de verilmiştir.

Tablo 7: Öğrenim Durumuna İlişkin Bulgular

\begin{tabular}{|c|c|c|c|}
\hline ÖĞRENiM DURUMU & Frekans & Yüzde & Kümülatif Yüzde \\
\hline Lise & 1 & .9 & .9 \\
\hline Üniversite & 90 & 78.3 & 79.1 \\
\hline Lisansüstü & 24 & 20.9 & 100.0 \\
\hline Toplam & 115 & 100.0 & \\
\hline
\end{tabular}

Firma çalışanlarının 90’’ üniversite, 24’ü lisansüstü ve 1'’i ise lise düzeyinde öğrenime sahiptir.

Korelasyon analizine ilişkin bulgular Tablo 8'de verilmiştir.

Tablo 8: Korelasyon Analizi

\begin{tabular}{|c|c|c|c|c|c|}
\hline & Ort. & Std. Sapma & Firma Performans 1 & $\begin{array}{l}\text { Tedarik Zinciri } \\
\text { Çevikliği }\end{array}$ & $\begin{array}{c}\text { Stratejik Kaynak } \\
\text { Kullanımı }\end{array}$ \\
\hline Firma Performans 1 & 3.90 & 0.53 & 1 & & \\
\hline $\begin{array}{l}\text { Tedarik Zinciri } \\
\text { Çevikliği }\end{array}$ & 4.27 & 0.52 & ,199* & 1 & \\
\hline $\begin{array}{c}\text { Stratejik Kaynak } \\
\text { Kullanımı }\end{array}$ & 3.99 & 0.62 &, $408^{* *}$ & $.172^{* *}$ & 1 \\
\hline
\end{tabular}

Korelasyon analizi neticesinde tedarik zinciri çevikliği ile firma performansı arasında 0,05 anlamlılık düzeyinde aynı yönde düşük, stratejik kaynak kullanımı ile firma performansı ve tedarik zinciri çevikliği arasında ise 0,01 anlamlılık düzeyinde aynı yönde düşük ilişki olduğu bulgusuna ulaşılmıştır. Ayrıca verilerin normal dağılıma sahip olup olmadığını test etmek amacıyla basıklık ve çarpıklık değerlerine bakılmıştır. Basıklık ve çarpıklık değerleri -2 ile +2 arasında tespit edildiğinden verilerin normal dağılıma sahip olduğu bulgusu elde edilmiştir.

\subsection{Araştırma Hipotezlerinin Test Edilmesi}

Araştırma hipotezlerini analiz edebilmek için öncelikli olarak bir yapısal eşitlik modeli kurulup analiz edilmiştir. Model Şekil 2'de, yapısal model uyum iyiliği değerleri Tablo 9'da ve yapısal model regresyon ağırlıkları Tablo 10'da sunulmuştur. 


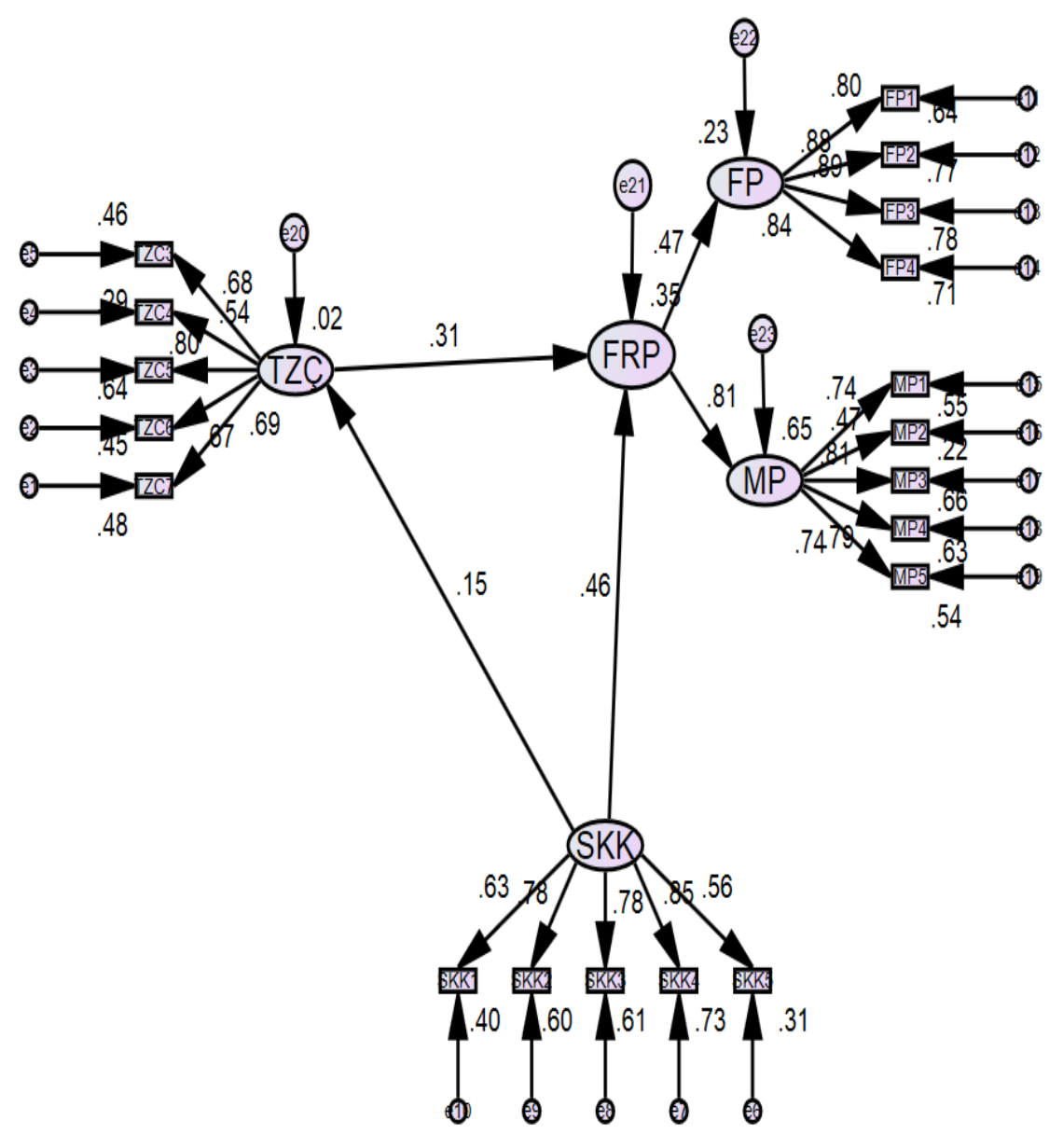

Şekil 2: Yapısal Eşitlik Modeli

Tablo 9: Yapısal Eşitlik Modeli Uyum İyiliği Değerleri

\begin{tabular}{|l|l|l|l|l|l|l|l|}
\hline & $\mathbf{X}^{\mathbf{2}}$ & df & CMIN/df & CFI & GFI & TLI & RMSEA \\
\hline $\begin{array}{l}\text { Yapısal Eşitlik } \\
\text { Modeli }\end{array}$ & 219.815 & 137 & 1.604 & 0.929 & 0.855 & 0.911 & 0.073 \\
\hline
\end{tabular}

Yapısal eşitlik modeli kabul edilebilir uyum iyiliği değerlerini sağlamakta ve iyi uyum göstermektedir. 
Tablo 10: Yapısal Eşitlik Modeli Regresyon Ağırlıkları

\begin{tabular}{|l|l|c|c|c|c|c|}
\hline \multicolumn{2}{|c|}{ Test Edilen Yol } & Tahmin & Std. Hata & $\begin{array}{c}\text { Kritik } \\
\text { Oran }\end{array}$ & P \\
\hline $\begin{array}{l}\text { Tedarik Zinciri } \\
\text { Çevikliği }\end{array}$ & $<---$ & $\begin{array}{c}\text { Stratejik Kaynak } \\
\text { Kullanımı }\end{array}$ & 0.145 & 0.124 & 1.248 & 0.012 \\
\hline Firma Performans1 & $<---$ & $\begin{array}{c}\text { Stratejik Kaynak } \\
\text { Kullanımı }\end{array}$ & 0.464 & 0.116 & 3.281 & 0.001 \\
\hline Firma Performans1 & $<---$ & $\begin{array}{c}\text { Tedarik Zinciri } \\
\text { Çevikliği }\end{array}$ & 0.305 & 0.105 & 2.228 & 0.026 \\
\hline
\end{tabular}

Yapısal eşitlik modelinin analizi neticesinde stratejik kaynak kullanımının tedarik zinciri çevikliği ve firma performansını pozitif yönde anlamlı olarak etkilediği, tedarik zinciri çevikliğinin de firma performansını pozitif yönde anlamlı olarak etkilediği bulgularına ulaşılmıştır. Analiz neticesinde H1, H2 ve H3 hipotezleri desteklenmiştir.

Tedarik zinciri çevikliğinin aracılık rolünü analiz edebilmek için Sobel testi yapılmıştır.

Üç ya da daha fazla değişkenin nedensel ardışıklığı söz konusu ise aracılık değişkeninden söz edilebilir. Bir değişken aşağıdaki şartları sağlıyorsa aracı değişken olarak ele alınır (Karagöz, 2016:953-954):

Bağımsız değişkenin bağımlı değişken üzerinde etkisi olmalıdır.

Bağımsız değişkenin aracı değişken üzerinde etkisi olmalıdır.

Aracı değişkenin bağımlı değişken üzerinde etkisi olmalıdır.

Aracı değişken bağımsız değişkenle birlikte modele dahil edldiğinde, bağımsız değişkenin bağımlı değişken üzerindeki etkisi azalırken, aracı değişkenin, bağımlı değişken üzerindeki etkisi anlamlı olmalıdır.

Bağımsız değişken ile aracı değişken birlikte regresyon analizine dahil edildiğinde, bağımsız değişken ile bağımlı değişken arasında anlamlı olamayan ilişki çıkarsa tam aracılık etkisi, bağımsız değişken ile bağımlı değişken arasındaki ilişkide azalma meydana gelirse kısmi aracılık etkisi meydana gelir (Girbüz ve Şahin, 2016:287; Baron ve Kenny,1986). 
Sobel Testi sonuçları Tablo 11'de sunulmuştur.

Tablo 11: Sobel Testi Sonuçları

\begin{tabular}{|c|c|c|c|c|}
\hline Adımlar & B & Std. Hata & $\boldsymbol{\beta}$ & $\mathbf{p}$ \\
\hline $\begin{array}{l}\text { 1.adım: } \\
\text { Bağımsız: Stratejik Kaynak } \\
\text { Kullanımı } \\
\text { Bağımlı: Firma Performansı }\end{array}$ & 0.424 & 0.118 & 0.494 & 0.000 \\
\hline $\begin{array}{l}\text { 2.Adım: } \\
\text { Bağımsız: Stratejik Kaynak } \\
\text { Kullanımı } \\
\text { Bağımlı: Tedarik Zinciri Çevikliği }\end{array}$ & 0.166 & 0.127 & 0.154 & 0.018 \\
\hline $\begin{array}{l}\text { 3. ve 4.Adım: } \\
\text { Bağımsız1: } \quad \text { Stratejik } \quad \text { Kaynak } \\
\text { Kullanımı } \\
\text { Bağımsız } \quad \text { 2: Tedarik } \quad \text { Zinciri } \\
\text { Çevikliği } \\
\text { Bağımlı: Firma Performansı }\end{array}$ & $\begin{array}{l}0.387 \\
0.323\end{array}$ & 0.115 & $\begin{array}{l}0.480 \\
0.445\end{array}$ & $\begin{array}{l}0.000 \\
0.004\end{array}$ \\
\hline
\end{tabular}

Tablo 11'de B, standardize edilmemiş, $\beta$ ise standardize edilmiş katsayı tahmin değerlerini göstermektedir. Sobel testi birinci aşamasında bağımsız değişken olan stratejik kaynak kullanımının firma performansını anlamlı olarak etkilediği, ikinci aşamasında bağımsız değişken olan stratejik kaynak kullanımının aracı değişkeni olan tedarik zinciri çevikliğini anlamlı olarak etkilediği bulgularına ulaşılmıştır. Bu aşamadan sonra stratejik kaynak kullanımı ve tedarik zinciri çevikliği değişkenleri bağımsız değişken olarak ve firma performansı da bağımlı değişken olarak analiz edilmiştir. Son aşamada da stratejik kaynak kullanımı ve tedarik zinciri çevikliği firma performansını anlamlı olarak etkilemiştir. Bu nedenle birinci aşama ve son aşamadaki stratejik kaynak kullanımının firma performansı üzerindeki etkisinde standardize edilmiş beta katsayı tahmin değerlerine bakılmıştır. Beta tahmin değerlerinde düşüş meydana geldiği görülmüştür (0,494'den 0,480 'e). Bu bulgu tedarik zinciri çevikliğinin kısmi aracılık rolü olduğunu göstermektedir. Analiz neticesinde H4 hipotezi desteklenmiştir.

\section{SONUÇ}

Firmaların stratejik kaynak kullanımının tedarik zinciri çevikliğine ve firma performansına etkisi, tedarik zinciri çevikliğinin firma performansına etkisi ve stratejik kaynak kullanımının firma performansı üzerindeki etkisinde tedarik zinciri çevikliğinin aracılık rolü bu çalışmanın konusu olmuştur.

Stratejik kaynak kullanımı, özellikle rekabetçi ortamlarda gerekli görülen ve firmalara rakiplerine karşı üstünlük elde etmelerini sağlayan bir stratejidir. Stratejik kaynak kullanımı, firmaların kaynaklarına proaktif olarak bakmasına, tedarikçilerini uzun vadeli planlarına dahil etmesine ve anahtar tedarikçilerle ilişkilerini geliştirmesine yardımcı olur. Birçok çalışma stratejik kaynak kullanımının firmaların fiansal ve finansal olmayan farklı performans türlerine 
pozitif yönde etki ettiğini göstermiştir (Carr ve Pearson, 1999; 2002; Carr ve Smeltzer, 1999; Chen vd. 2004; Jin ve Farr, 2010; Narasimhan ve Das, 1999a). Çalışmamızda ise bu konu stratejik kaynak kullanımınının firma performansını pozitif yönde etkileyeceği doğrultuda bir hipotezle araştırılmış ve doğrulanmıştır. Bulgular stratejik kaynak kullanımı eğilimi gösteren firmaların performanslarını arttırdığını göstermektedir.

Araştırmada incelenen bir diğer konu ise stratejik kaynak kullanımının tedarik zinciri çevikliği üzerideki etkisidir. Literatürde de birçok kez görüldüğü üzere stratejik kaynak kullanımı tedarik zinciri çevikliğini pozitif yönde etkilemektedir (Khan ve Pillania, 2008; Mason vd. 2002; Narasimhan ve Das, 1999a; Paulraj ve Chen, 2007b). Çalışmamız önceki çalışmaları desteklemiş ve benzer sonuçlar sunmuştur. $\mathrm{Bu}$ sonuçlar, stratejik kaynak kullanımının işletmelerin tedarik zinciri çevikliğini arttırdığını, bu şekilde değişikliklere karşı daha hızlı adapte olabildiğini ve cevap verebildiğini ifade etmektedir. Stratejik satın alma, olası uzun vadeli bir ortaklığın geliştirilmesi için bir grup stratejik tedarikçinin seçilmesine yardımcı olur. İç entegrasyon, satın almay, tasarım, Ar-Ge ve üretim fonksiyonlarının ihtiyaçlarını anlamasını sağlar. Stratejik kaynak kullanımının bu iki unsuru işletmenin iç fonksiyonları ile dış tedarkçileri arasında stratejik satın alma fonksiyonu ile koordinasyon sağlar. Bilgi paylaşımı ve tedarikçi geliştirme faaliyetleri, firma ile seçilmiş tedarikçiler arasındaki ilişkiyi geliştirir. $\mathrm{Bu}$ yakın ilişkiler ve stratejik satınalma, işletmelerin birlikte planlar yapmalarına, pazardaki talep değişimlerne hızlı cevap verebilmelerine ve müşterilerin özellikli ürün ihtiyaçlarını karşılayabilmelerine temel oluşturur. Böylelikle işletmeler stratejik kaynak kullanımı sayesinde tedarik zinciri çevikliğini arttırarak daha yüksek performans sergileyebilirler.

Büyük firmaların ölçek ekonomileri sayesinde daha az birim maliyetlerle daha yüksek performans gösterdiği düşüncesi son zamanlarda kesinliğini kaybetmiştir. Meselenin büyüklükten ziyade çeviklik ilişkili olduğunu anlayan işletmeler tedarik zincirlerini daha çevik bir yapıda tasarlamaya önem vermeye başlamıştır. Birçok bilimsel çalışmaya da konu olan tedarik zinciri çevikliğinin firma performansına etkisi incelenmiş ve önemli etkiler bulunmuştur (Tallon ve Pinsonneault, 2011; Swafford vd. 2008; Yusuf ve Adeleye, 2002). Çalışmamızda da tedarik zinciri çevikliğinin firma performansına etkisi pozitif ve anlamlı olarak bulgulanmıştır. Daha öncede bahsedildiği gibi tedarik zinciri çevikliği, firmaların talep değişimlerini önceden algılama ve cevap verebilme hızı ile ilgilidir. Dolayısıyla pazarda oluşacak değişimlere daha hızlı cevap veren firmaların daha çok performans sergilediği ispatlanmıştır.

Son olarak çalışmada stratejik kaynak kullanımının firma performansı üzerindeki etkisinde tedarik zinciri çevikliğinin aracılık rolü incelenmiştir. Tedarik zinciri çevikliğinin 
farklı değişkenlerle performans arasındaki ilişkide aracılık rolü birçok çalışmada bulgulanmıştır (Vickery vd. 2010; Swafford vd. 2008; Rexhausen 2013; Chan, Ngai ve Moon 2017). Ancak çalışmamızda Chiang, Kocabasoglu-Hillmer ve Suresh (2012)'nin çalışmasındaki gibi kısmi aracılık görülmüştür. Farklı olan sadece Chiang, Kocabasoglu-Hillmer ve Suresh (2012)'nin stratejik kaynak kullanımının tedarik zinciri çevikliği üzerindeki etkisinde stratejik esnekliğin aracılık rolünü araştırmış olmasıdır. Daha öncede bahsedildiği gibi esneklik ve çeviklik farklı kavramlardır. Ancak her ikiside pazardaki değişimlere cevap verebilme ile ilgili olduğu için çalışmamızın sonuçlarının sözü geçen çalışmaya benzemesi olağan görülmüştür. Böylelikle stratejik kaynak kullanımının firma performansı üzerindeki etkisine tedarik zinciri çevikliğinin kısmi olarak aracılık ettiği söylenebilmektedir. 


\section{KAYNAKÇA}

Baron R.M. ve Kenny D.A. (1986). The moderator-mediator variable distinction in social psychological research: Conceptual, strategic and statistical considerations. Journal of Personality and Social Psychology,51, 1173-1182

Belussia F., Sammarrab A., Sedita S.R. (2010). Learning at the boundaries in an "Open Regional Innovation System": A focus on firms' innovation strategies in the Emilia Romagna life science industry. Research Policy 39 (2010) 710721

Bidhandi R.A. ve Changiz Valmohammadi C., (2017). Effects of supply chain agility on profitability, Business Process Management Journal, Vol. 23 Issue: 5, pp.1064-1082.

Blome, C., Schoenherr, T. ve Rexhausen, D. (2013) Antecedents and enablers of supply chain agility and its effect on performance: a dynamic capabilities perspective, International Journal of Production Research, 51:4, 1295-1318,

Carr, A. S. ve Pearson, J. N. (1999), "Strategically managed buyer-supplier relationships and performance outcomes", Journal of Operations Management, Vol. 17, pp. 497-519.

Carr, A. S. ve Pearson, J. N. (2002), "The impact of purchasing and supplier involvement on strategic purchasing and its impact on firm's performance”, International Journal of Operations and Production Management, Vol. 22, pp. 1032-1053.

Carr, A.S. ve Smeltzer, L. (1999), “The relationship of strategic purchasing to supply chain management”, European Journal of Purchasing and Supply Management, Vol. 5, pp. 43-51.

Chan, A.T.L., Ngai, E.W.T. ve Moon, K.K.L. (2017). The effects of strategic and manufacturing flexibilities and supply chain agility on firm performance in the fashion industry. European Journal of Operational Research 259:486-499

Chan T.C.T. ve Chin K.S., (2007) "Key success factors of strategic sourcing: An empirical study of the Hong Kong toy industry", Industrial Management \& Data Systems, Vol. 107 Issue: 9, pp.1391-1416.

Chen, I. J., Paulraj, A. ve Lado, A. A. (2004), "Strategic purchasing, supply management, and firm performance”, Journal of Operations Management, Vol. 22, pp. 505-523.

Chiang, C.Y., Kocabasoglu-Hillmer, C. ve Suresh, N. (2012). An empirical investigation of the impact of strategic sourcing and flexibility on firm's supply chain agility. International Journal of Operations and Production Management, 32(1-2), pp. 49-78.

Çalışkan, A., Karacasulu, M. T. ve Öztürkoğlu, Y. (2016). Hızlı Moda Markalarında Çevik ve Esnek Tedarik Zinciri Yönetimi. MCBÜ Sosyal Bilimler Dergisi, 14:4, S. 49-74

DeGroote, S.E. ve Marx, T.G. (2013). The impact of IT on supply chain agility and firm performance: Anempirical investigation. International Journal of Information Management 33 909-916

De Guimarães, J. C. F., Severo, E. A., Dorion, E. C. H., Coallier, F. ve Olea, P. M. (2016). The use of organisational resources for product innovation and organisational performance: a survey of the Brazilian furniture industry. International Journal of Production Economics, 180, 135-147.

Gligor, D. M., Esmark. C. L. ve Holcomb, M. C. (2015). Performance outcomes of supply chain agility: When should you be agile? Journal of Operations Management 33:34, S.71-82

Gligor, D.M., ve Holcomb, M.C,. (2012). Antecedents and Consequences of Supply Chain Agility: Establishing the Link to Firm Performance. Journal of Business Logistics, 33(4): 295-308

Goldman, S.L., Nagel, R.N. and Preiss, K. (1994), Agile Competitors and Virtual Organizations: Strategies for Enriching the Customer, Van Nostrand Reinhold, New York, NY.

Gürbüz, S. ve Şahin, F. (2016). Sosyal bilimlerde araştırma yöntemleri felsefe, yöntem, analiz (3. bs.). Ankara: Seçkin Yayıncilik.

Hawkins T.G., Nissen M.E., Rene G. Rendon R.G. (2014) "Leveraging strategic sourcing and knowledge management to improve the acquisition of knowledgebased services", Journal of Public Procurement, Vol. 14 Issue: 2, pp.215251.

Hwang, D., Yang, M. G. M. ve Hong, P. (2015). Mediating effect of IT-enabled capabilities on competitive performance outcomes: An empirical investigation of ERP implementation. Journal of Engineering and Technology Management, 36, 1-23. 
Inman, R.A., Sale, R.S., Green Jr., K.W. ve Whitten, D., 2011. Agile manufacturing: rela-tion to JIT, operational performance and firm performance. J. Oper. Manage. 29(4), 343-355.

Jennings, J., ve Haughton, L. (2002). It's not the BIG that eat the SMALL... it's the FAST that eat the SLOW: How to Use Speed as a Competitive Tool in Business. Harper Collins.

Jin, B. ve Farr, C.A. (2010), "Supplier selection criteria and perceived benefits and challenges of global sourcing apparel firms in the United States", Family and Consumer Sciences Research Journal, Vol. 39 No. 1, pp. 31-44.

Kafetzopoulos, D., Gotzamani, K. ve Psomas, E. (2013). Quality systems and competitive performance of food companies. Benchmarking: An International Journal, 20(4), 463-483.

Kafetzopoulos, D., Gotzamani, K. ve Gkana, V. (2015). Relationship between quality management, innovation and competitiveness. Evidence from Greek companies. Journal of Manufacturing Technology Management, 26(8), 1177-1200.

Kang, M., Wu, X. ve Hong, P. (2009), "Strategic outsourcing practices of multi-national corporations (MNCs) in China”, Strategic Outsourcing: An International Journal, Vol. 2 No. 3, pp. 240-56.

Karagöz, Y. (2016). SPSS ve AMOS 23 uygulamalı istatistiksel analizler (1. bs.). Ankara: Nobel Akademik Yayıncılık.

Khan, A.K. ve Pillania, R.K. (2008) "Strategic sourcing for supply chain agility and firms' performance: A study of Indian manufacturing sector", Management Decision, Vol. 46 Issue: 10, pp.1508-1530

Kim, M., Suresh, N. ve Kocabasoglu-Hillmer, C. (2015). A contextual analysis of the impact of strategic sourcing and Eprocurement on performance. Journal of Business and Industrial Marketing, 30(1), pp. 1-18.

Kim M. ve Chai S. (2017). The impact of supplier innovativeness, information sharing and strategic sourcing on improving supply chain agility: Global supply chain perspective. International Journal of Production Economics 187 (2017) 42-52.

Landale K.A.F., Apte A., Rendon R.G., Salmerón J. (2018) "Using analytics to inform category management and strategic sourcing", Journal of Defense Analytics and Logistics, https://doi.org/10.1108/JDAL-06-2017-0010.

Liu H., Weiling Ke W., Wei K.K., Hua Z. (2013). The impact of IT capabilities on firm performance: The mediating roles of absorptive capacity and supply chain agility. Decision Support Systems 54 (2013) 1452-1462.

Mason, S. J., M. H. Cole, B. T. Ulrey ve L. Yan (2002), "Improving electronics manufacturing supply chain agility through outsourcing", International Journal of Physical Distribution \& Logistics Management, Vol.32 No.7, pp.610 - 620.

Narasimhan, R. ve Das, A. (1999a). An Empirical Investigation of the Contribution of Strategic Sourcing to Manufacturing Flexibilities and Performance. Decision Sciences Volume 30 Number 3

Narasimhan, R. ve Das, A. (1999b), "Manufacturing agility and supply chain management practices", Production \& Inventory Management Journal, Vol.40 No.1, pp.7 - 10.

Nayyar, P.R. ve Bantel, K.A. (1994), “Competitive agility: a source of competitive advantage based on speed and variety”, Advances in Strategic Management, Vol. 10 No. 1, pp. 193-222.

Paulraj, A. ve Chen, I.J. (2007a), "Environmental uncertainty and strategic supply management: a resource dependence perspective and performance implications", Journal of Supply Chain Management, Vol. 43 No. 3, pp. $29-42$.

Paulraj, A. ve Chen, I.J. (2007), "Strategic buyer-supplier relationships, information technology and external logistics integration", Journal of Supply Chain Management, Vol.43 No.2, pp.2 - 14.

Sanchez A.M. ve Leo F.L., (2018) "Supply chain agility: a mediator for absorptive capacity", Baltic Journal of Management, Vol. 13 Issue: 2, pp.264-278.

Sinha, P., Akoorie, M.E.M., Ding, Q. ve Wu, Q. (2011), "What motivates manufacturing SMEs to outsource offshore in China?: comparing the perspectives of SME manufacturers and their suppliers",Strategic Outsourcing: An International Journal, Vol. 4 No. 1, pp. 67-88.

Su, J. ve Gargeya, V.B. (2012). Strategic sourcing, sourcing capability and firm performance in the U.S. textile and apparel industry. Strategic Outsourcing: An International Journal, 5(2): 145-165.

Su J., (2013) "Strategic sourcing in the textile and apparel industry", Industrial Management \& Data Systems, Vol. 113 Issue: 1, pp.23-38.

Swafford, P. M., Ghosh, S., ve Murthy, N. (2008). Achieving supply chain agilitythrough IT integration and flexibility. 
International Journal of Production Eco-nomics, 116, 288-297.

Swafford P.M., Ghosh S., Murthy N. (2006). The antecedents of supply chain agility of a firm: Scale development and model testing. Journal of Operations Management 24 (2006) 170-188.

Tallon, P. P. ve Pinsonneault, A. (2011). Competing perspectives on the link between strategic information technology alignment and organizational agility: insights from a mediation model. MIS Quarterly, 35(2), ss.463-486.

Tan, K.C., Lyman, S.B. ve Wisner, J.D. (2002), "Supply chain management: a strategic perspective”,International Journal of Operations \& Production Management, Vol. 22 No. 6, pp. 614-31.

Teece, D.J., Pisano, G. ve Shuen, A. (1997), "Dynamic capabilities and strategic management" Strategic Management Journal, Vol. 18 No. 7, pp. 509-33.

Um J. (2017). Improving supply chain flexibility and agility through variety management", The International Journal of Logistics Management, Vol. 28 Issue: 2, pp.464-487.

Vazquez-Bustelo, D., Avella, L. ve Fernandez, E., 2007. Agility drivers, enablers andoutcomes: empirical test of an integrated agile manufacturing model. Int. J. Oper.Prod. Manage. 27 (12), 1303-1332.

Vickery, S.K., Droge, C., Setia, P. ve Sambamurthy, V. (2010). Supply chain information technologies and organisational initiatives: complementary versus independent effects on agility and firm performance. International Journal of Production Research, 48 (23),7025-7042.

Yang, J. (2014). Supply chain agility: Securing performance for Chinese manufacturers. Int. J.ProductionEconomics150:104-113

Yusuf, Y., ve Adeleye, E. (2002). A comparative study of lean and agile manu-facturing with a related survey of current practices in the UK. InternationalJournal of Production Research, 40(17), 4545-4562. 